J. Clin. Chem. Clin. Biochem.

Vol. 27. 1989, pp. 539-545

(C) 1989 Walter de Gruyter \& Co.

Berlin - New York

\title{
Gastric Ulcer is Accompanied by a Decrease of Epidermal Growth Factor in Gastric Juice and Saliva
}

\author{
By G. Hansen, C. Müller, P. Sinha
}

Institut für klinische Chemie und Biochemie, Freie Universität Berlin, Universitätsklinikum Rudolf Virchow, Berlin, F.R.G.

\section{W. Bohnenkamp}

Byk Gulden Pharmazeutika Konstanz, F.R.G. and

\section{E. Köttgen}

Institut für klinische Chemie und Biochemie, Freie Universität Berlin, Universitätsklinikum Rudolf Virchow, Berlin, F.R.G.

(Received April 3/June 15, 1989)

Summary: Numerous studies have indicated a role of epidermal growth factor in the maintenance of the gastrointestinal mucosa.

In the present study epidermal growth factor concentrations in saliva and gastric juice of patients with gastric or duodenal ulcer or gastritis are compared with those of healthy controls. For this purpose a novel ELISA system has been developed and shown to be sensitive and specific.

It is demonstrated that gastric juice and saliva of patients with gastric ulcer contain less epidermal growth factor than the samples of healthy controls $(p<0.01)$. Epidermal growth factor concentrations and outputs (product of epidermal growth factor concentration and the volume secreted in $15 \mathrm{~min}$ ) in the gastric juice of patients with duodenal ulcer do not differ from those of healthy controls.

\section{Introduction}

Epidermal growth factor is a single-chain polypeptide of $M_{\mathrm{r}} 6000$ consisting of 53 amino acids $(1,2)$. Epidermal growth factor produces a variety of biological responses including enhanced proliferation and differentiation of epithelial tissues in vivo and in vitro. Numerous target structures and different modes of action reveal similarities between epidermal growth factor and polypeptide hormones such as insulin (3).

Epidermal growth factor has been detected in almost all body fluids, whereas synthesis in man has so far only been shown in Brunner glands of the duodenum and salivary glands, the parotid gland being the major source of synthesis and secretion (4).

The role of epidermal growth factor in the pathogenesis of gastrointestinal ulcer disease has received much attention in the past few years. The "rediscovery" of Campylobacter pylori demonstrates that the "ulcer discussion" is still controversial (5). The purpose of the present study is the further elucidation of the possible involvement of epidermal growth factor in ulcer disease.

High concentrations of epidermal growth factor have been known for a long time to inhibit gastric secretion 
(6). Apart from this artificial effect, many findings suggest that it participates in the maintenance of the gastrointestinal mucosa $(7,8)$. These studies, however, are based on animal models. The earliest data on the concentration of epidermal growth factor in the saliva of patients with gastrointestinal ulcer, compared with healthy controls, were reported by Ohmura et al. (9). As these results could not be confirmed in our investigations, definite evidence is still lacking that epidermal growth factor in human gastrointestinal ulcer disease is subject to any alteration.

The present study was performed in order to examine epidermal growth factor concentrations in saliva and gastric juice of patients with gastrointestinal complaints (gastric ulcer, duodenal ulcer, gastritis) and healthy controls. The use of a sensitive, specific and practicable assay system for routine measurement is a prerequisite, in order to establish the pathophysiological role or even clinical relevance of epidermal growth factor in various body fluids. In this paper we present the development of a novel ELISA for human epidermal growth factor, which involves some unusual processing stages. This assay is less time-consuming than any comparable assay published, and it meets all requirements mentioned above.

\section{Materials and Methods}

\section{Reagents}

Goat-IgG $F\left(a b^{\prime}\right)_{2}$ : anti mouse-IgF (Fc) was obtained from Jackson, Dianova, Hamburg, FRG; human epidermal growth factor (human urine), rabbit anti mouse-epidermal growth factor. streptavidin-peroxidase') from Calbiochem, Frankfurt, FRG; rabbit serum from Gibco, Karlsruhe, FRG; NHS-LCbiotin (N[6-(biotinamido)hexanoyloxy]sulphosuccinimide) from Pierce, Oud Beijerland, Netherlands; 3,3',5,5'-tetramethylbenzidine (TMB) from Fluka, Buchs, Switzerland; mouse monoclonal anti human-epidermal growth factor antibodies from AMGEN, Thousand Oaks, California, USA.

Rabbit anti human-epidermal growth factor antiserum was kindly provided by Dr. H. Gregory, ICI, Macclesfield, UK.

\section{Equipments}

Microtitre plates, high binding capacity, from Nunc, Wiesbaden, FRG and a Titertek Multiscan photometer from Flow Laboratories Meckenheim, FRG connected to an Epson HX 20 were used.

\section{Samples and patient collectives}

Saliva, gastric juice and spontaneous urine were collected from healthy volunteers and patients between 07.00 and $11.30 \mathrm{AM}$ after a fasting period of 12 hours. Patients discontinued the use of drugs 36 hours before examination. Samples of gastric juice were obtained by aspirating $2-3 \mathrm{ml}$ through a sample collector using the instrument channel of the endoscope. No lavage fluid

1) Enzymes: Horseradish peroxidase (donor: hydrogen peróxide oxidoreductase, EC 1.11.1.7). was used before sample withdrawal. The endoscopies were performed for sound medical reasons and not for the purpose of the present investigation.

Total 15 minutes output could be measured by aspiration, using gastric tubes (UNO) that were placed in the antrum under $X$ ray control.

Epidermal growth factor concentration was measured in gastric juice of patients with acute gastric ulcers $(n=9)$, gastric ulcers under treatment $(2 \times 40 \mathrm{mg} / \mathrm{d}$ famotidín $)(n=9)$, duodenal ulcers $(n=14)$, gastritis $(n=22)$ and healthy controls $(n=19)$.

The 15-minute-output of epidermal growth factor was determined in the gastric juice of patients with treated gastric ulcer $(n=8)$, duodenal ulcer $(n=6)$, gastritis $(n=7)$ and healthy controls $(n=14)$.

Saliva $(2-3 \mathrm{ml})$ was collected without stimulation before endoscopic examination from patients with gastric ulcer (treated and untreated) $(n=11)$, patients with duodenal ulcer $(n=4)$, and patients with gastritis $(n=10)$. Total saliva secretion in defined periods could not be ascertained due to the disturbance and interruption of routine endoscopy. Saliva samples and 15minute gastric juice volumes were collected from the same patients who underwent sample collection during endoscopic examination. Patients with acute gastric ulcer and with ulcer under treatment were different individuals. For saliva examination gastric ulcer patient groups were not separated into acute and treated gastric ulcer.

All diagnoses were confirmed by endoscopy and histology. In the case of patients with treated ulcers, samples were collected during control endoscopy or after control endoscopy (for output-determination), respectively.

All samples were centrifuged at $15000 \mathrm{~g}$ for 5 minutes and stored at $-40^{\circ} \mathrm{C}$ until use.

\section{Biotinylated immunoglobulins}

Immunoglobulin fractions were prepared from whole antisera by repeated ammonium sulphate precipitation at 0.40 saturation. After redissolving the pellet in distilled water, the sample was desalted by chromatography on Sephadex G-25 fine, equilibrated with $0.015 \mathrm{~mol} / \mathrm{l}$ sodium phosphate, $\mathrm{pH} 7.4$. The protein concentration of the eluate was determined according to Bradford (10).

Immunoglobulins in $0.015 \mathrm{~mol} / 1$ phosphate buffer, $\mathrm{pH} 7.4$, were incubated with NHS-LC-biotin (molar ratio of biotin to IgG approximately $30: 1$ ) for three days at $6^{\circ} \mathrm{C}$. The mixture was then diluted with 1 volume ethylene glycol and stored at $-20^{\circ} \mathrm{C}$.

\section{Epidermal growth factor-ELISA}

Microtitre-plates were coated by adding $150 \mu \mathrm{l}$ of a 1:250 dilution (v/v) goat-F $\left(\mathrm{ab}^{\prime}\right)_{2}$ anti mouse-IgG (Fc) in $0.015 \mathrm{~mol} / \mathrm{l}$ phosphate buffer, $\mathrm{pH} 7.4$. After 2 hours, the microtitre plates were washed $3 \times$ with wash buffer $(0.015 \mathrm{~mol} / \mathrm{l}$ phosphate buffer, pH 7.4 containing $1 \mathrm{~g} / 1$ Tween 20 ) and $1 \times$ with distilled water, vacuum-dried and stored desiccated at $4{ }^{\circ} \mathrm{C}$ for up to 6 months.

Standards at $0.05,0.1,0.2,0.5,1$ and $2 \mu \mathrm{g} / \mathrm{l}$ in assay buffer $(\cdot 10$ $\mathrm{ml} / \mathrm{l}$ rabbit serum in wash buffer) were prepared daily from a $10 \mathrm{mg} / \mathrm{l}$ stock human epidermal growth factor solution in ethylene glycol volume fraction 0.50 stored in aliquots at $-20^{\circ} \mathrm{C}$.

Serum samples were used undiluted; saliva at a $1: 2$ dilution, urines at a 1:50 and a 1:500 (v/v) dilution in assay buffer; gastric juice at a $1: 2(\mathrm{v} / \mathrm{v})$ dilution in $0.15 \mathrm{~mol} / 1$ phosphate buffer, $\mathrm{pH} 7.4$ (which adjusts the $\mathrm{pH}$ of the gastric juice to above $7: 0$ ). 
For the assay, $60 \mu \mathrm{l}$ of standard or sample were placed in duplicate into consecutive wells of a coated microtitre plate. An $8 \mathrm{~h}$ incubation period at room temperature was started by adding $90 \mu \mathrm{l}$ of an antibody mixture containing the monoclonal anti epidermal growth factor at a 1:90000 dilution and the biotinylated rabbit anti epidermal growth factor at a 1:9000 dilution in assay buffer.

After 2 washes, $150 \mu \mathrm{l}$ streptavidin-peroxidase at a 1:5000 dilution in assay buffer were added for $30 \mathrm{~min}$.

After 6 washes, $150 \mu \mathrm{l}$ tetramethylbenzidine substrate solution in $\mathrm{pH} 3.95$ citrate $/ \mathrm{H}_{2} \mathrm{O}_{2}$ buffer (11) were added and left for 10 min. The reaction was stopped by addition of $50 \mu \mathrm{l} 2 \mathrm{~mol} / \mathrm{l}$ sulphuric acid and the absorbance read at 450 and $492 \mathrm{~nm}$ (measuring and reference wavelength, respectively).

The test scheme is illustrated in figure 1.

\section{Statistical analysis}

Statistical differences were evaluated by the U-test according to Wilcoxon, Mann \& Whitney (12).

\section{Results}

Our new ELISA procedure yields a linear standard curve with epidermal growth factor concentrations up to $2 \mu \mathrm{g} / 1$ (fig. 2). The lower detection limit of epidermal growth factor in body fluids can be considered to be approximately $20 \mathrm{ng} / 1$ (determined by calculating the mean \pm 3 SD of 8 replicate measurements of the zero sample). Within the measuring range (0.02$2 \mu \mathrm{g} / \mathrm{l})$ the maximal intra- and interassay imprecision was $5 \%$ and $9 \%$, respectively.

A

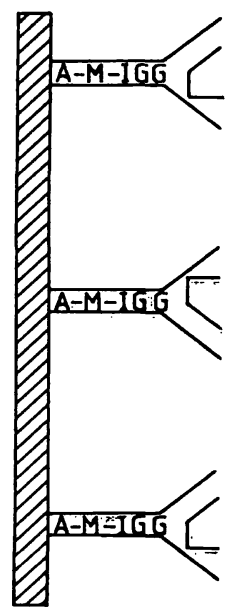

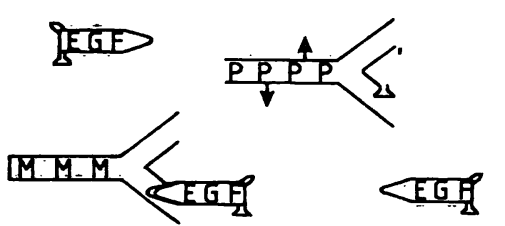

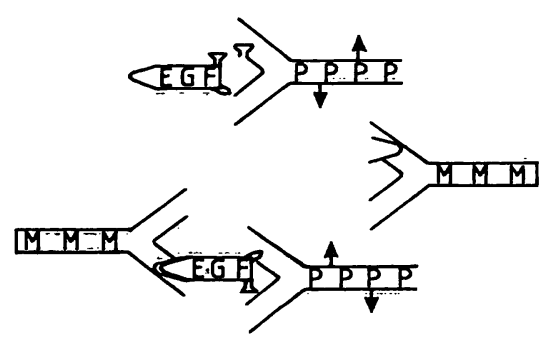

As an indication of test linearity, the dilution curves of different sample materials are demonstrated in figure 3. The coefficient of correlation $(r)$ of the dilutions $1: 32$ to $1: 2$ with their measured concentrations is 0.97 .

When defined amounts of epidermal growth factor were added to different sample material, the recovery was $92 \%-103 \%$ (tab. 1 ).

No sex or age-dependent differences in epidermal growth factor concentration were noticed in saliva or gastric juice of healthy controls.

Four healthy volunteers endured our "thirst-experiments" in which 5-minute-saliva-samples were collected at $08.00 \mathrm{AM}$ after 12 hours thirst/fasting period. After another 4 hours period a second 5-minutesaliva-sample was obtained. Thirty minutes after water substitution $(0.71$ mineral water following a thirst/fasting period lasting over $16 \mathrm{~h}$ ) a third 5-minute-saliva-sample was obtained from the volunteers.

The results suggest that concentrations of epidermal growth factor in saliva increase after longer thirst/ fasting periods and descend to approximately half their original values after water substitution (tab. 2). The calculated output of epidermal growth factor and the ratio of epidermal growth factor concentration to the concentration of total protein seem to be nearly constant during thirst and after water substitution.

Fig. 1. Schematic representation of the human epidermal growth factor ELISA.

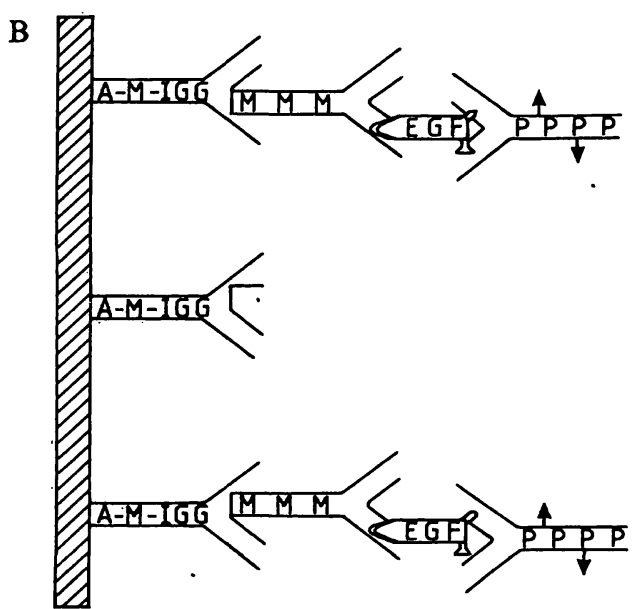

A. First incubation with mouse monoclonal anti human epidermal growth factor, standard/sample, biotin-conjugated rabbit polyclonal anti human epidermal growth factor.

B. Assay system after the washing cycles before addition of avidin-peroxidase.

$$
\begin{aligned}
& =\text { goat anti mouse IgG (Fc). } \\
& =\text { mouse monoclonal anti human epidermal growth factor. } \\
& =\text { = rabbit polyclonal anti human epidermal growth factor. }
\end{aligned}
$$




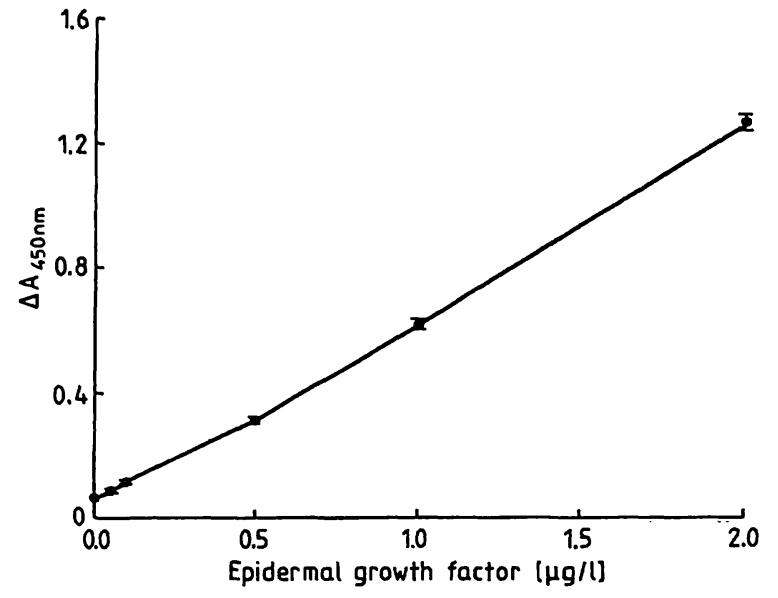

Fig. 2. Epidermal growth factor standard curve.

Plot of absorbance $(450 \mathrm{~nm})$ of different standard dilutions against concentration. All values are mean of duplicate measurements. The coefficient of variation is less than $4 \%$.

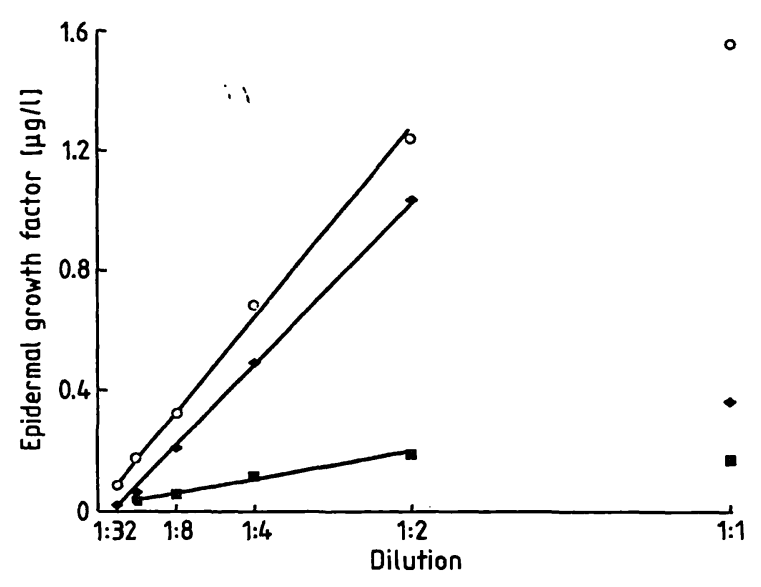

Fig. 3. Epidermal growth factor concentration in sample dilution.

Plot of concentrations at different dilutions of various body fluids against numeric dilution. Good linearity ( $r>0.97$ ) is obtained from $1: 2$ to $1: 32$ dilution. Concentrations in undiluted $(1: 1)$ samples are decreased due to low $\mathrm{pH}$ or high sample viscosity.

0 = Saliva

$\diamond=$ Saliva

$\square$ = Duodenal juice

No significant differences were noticed in epidermal growth factor concentrations in saliva. The group of gastric ulcer patients, however, showed decreased ratios of epidermal growth factor concentration to the cencentration of total protein $(p<0.01$ compared with healthy control) (tab. 3 and fig. 5).

Results of gastric juice measurements are demonstrated in table 4 and figure 4 . A significant difference in epidermal growth factor concentration and 15minute-output was seen between gastric ulcer patients and healthy controls $(\mathrm{p}<0.01)$.
Tab. 1. Concentrations of epidermal growth factor in gastric juice ( $1: 2$ in $0.15 \mathrm{~mol} / 1$ phosphate buffer, $\mathrm{pH} 7.4)$, saliva $(1: 2$ in $0.015 \mathrm{~mol} / 1$ phosphate buffer, $\mathrm{pH} 7.4)$ and serum before and after addition of 3 and $6 \mu$ epidermal growth factor standard solution $(16 \mu \mathrm{g} / \mathrm{l})$ to $200: \mu \mathrm{l}$ sample.

\begin{tabular}{|c|c|c|c|c|c|}
\hline & \multicolumn{5}{|c|}{ Epidermal growth factor [ng/1] } \\
\hline & \multirow{2}{*}{$\begin{array}{l}0 \mu l \text { added } \\
\text { Found }\end{array}$} & \multicolumn{2}{|c|}{$3 \mu \mathrm{l}$ added } & \multicolumn{2}{|c|}{$6 \mu l$ added } \\
\hline & & $\begin{array}{l}\text { Calcu- } \\
\text { lated }\end{array}$ & Found & $\begin{array}{l}\text { Calcu- } \\
\text { lated }\end{array}$ & Found \\
\hline $\begin{array}{l}\text { Gastric juice } \\
\text { Saliva } \\
\text { Serum }\end{array}$ & $\begin{array}{r}540 \\
1 \overline{2} 90 \\
130\end{array}$ & $\begin{array}{r}776 \\
1526 \\
366\end{array}$ & $\begin{array}{r}720 \\
1480 \\
370\end{array}$ & $\begin{array}{r}1006 \\
1756 \\
596\end{array}$ & $\begin{array}{r}980 \\
1690 \\
610\end{array}$ \\
\hline
\end{tabular}

Tab. 2. Epidermal growth factor concentration, ratio of epidermal growth factor concentration to total protein concentration and product of concentration and volume ("output") in saliva samples, collected over a period of 5 minutes from 4 probands after thirst/fasting periods of 12 and 16 hours and after water substitution (mean \pm SD).

\begin{tabular}{llll}
\hline & \multicolumn{3}{l}{ Epidermal growth factor } \\
\cline { 2 - 4 } & {$[\mu \mathrm{g} / \mathrm{l}]$} & {$[\mu \mathrm{g} / \mathrm{g}$ protein] } & {$[\mathrm{ng} / 5 \mathrm{~min}]$} \\
\hline Thirst $(12 \mathrm{~h})$ & $3.0 \pm 0.7$ & $7.9 \pm 1.1$ & $6.9 \pm 1.2$ \\
Thirst $(16 \mathrm{~h})$ & $3.8 \pm 0.8$ & $7.7 \pm 1.3$ & $6.1 \pm 1.0$ \\
Water & $1.5 \pm 0.4$ & $6.8 \pm 0.9$ & $5.7 \pm 1.4$ \\
substitution & & & \\
\hline
\end{tabular}

Tab. 3. Concentrations of epidermal growth factor in saliva and ratio of epidermal growth factor concentration to. total protein concentration (mean $\pm S D$ ).

\begin{tabular}{lrll}
\hline & & \multicolumn{2}{l}{ Epidermal growth factor } \\
\cline { 2 - 4 } & $\mathrm{n}$ & {$[\mu \mathrm{g} / \mathrm{l}]$} & {$[\mu \mathrm{g} / \mathrm{g}$ protein] } \\
\hline Controls & 12 & $3.72 \pm 1.63$ & $5.50 \pm 0.80$ \\
Gastric ulcer & 11 & $2.25 \pm 1.64$ & $2.46 \pm 1.02^{* *}$ \\
Duodenal ulcer & 4 & $3.14 \pm 1.25$ & $4.30 \pm 0.60$ \\
Gastritis & 10 & $4.28 \pm 1.86$ & $5.62 \pm 1.40$ \\
\hline
\end{tabular}

$* *=p<0.01$ compared with all other groups

The 15-minute output of epidermal growth factor in patients with gastric ulcer was 5 times lower, and the epidermal growth factor concentration was even 10 times lower than in controls. The values for patients with duodenal ulcer or gastritis did not differ from those of the control group.

The amounts of epidermal growth factor excreted in the urine, based on creatinine, did not differ significantly between the examined collectives.

J. Clin. Chem. Clin. Biochem. / Vol. 27, 1989 / No. 9 
Tab. 4 Epidermal growth factor concentrations and 15 min output in gastric juice of control group and patients (mean \pm SD).

\begin{tabular}{|c|c|c|c|c|}
\hline & \multicolumn{4}{|c|}{ Epidermal growth factor } \\
\hline & {$[\mu \mathrm{g} / \mathrm{l}]$} & & [ng/15 min] & \\
\hline $\begin{array}{l}\text { Healthy probands } \\
\text { Acute gastric ulcer } \\
\text { Treated gastric ulcer } \\
\text { Duodenal ulcer } \\
\text { Gastritis }\end{array}$ & $\begin{array}{l}1.19 \pm 0.8 \\
0.14 \pm 0.08 \\
0.16 \pm 0.14 \\
0.90 \pm 0.58 \\
1.38 \pm 1.0\end{array}$ & $\begin{array}{l}(n=19) \\
(n=9)^{* *} \\
(n=9)^{* *} \\
(n=14) \\
(n=22)\end{array}$ & $\begin{array}{l}26.4 \pm 15.3 \\
\text { not determined } \\
4.80 \pm 3.9 \\
25.5 \pm 23.3 \\
28.2 \pm 5.6\end{array}$ & $\begin{array}{l}(n=14) \\
(n=8)^{* *} \\
(n=6) \\
(n=7)\end{array}$ \\
\hline
\end{tabular}

** $=\mathrm{p}<0.01$ compared with healthy controls.

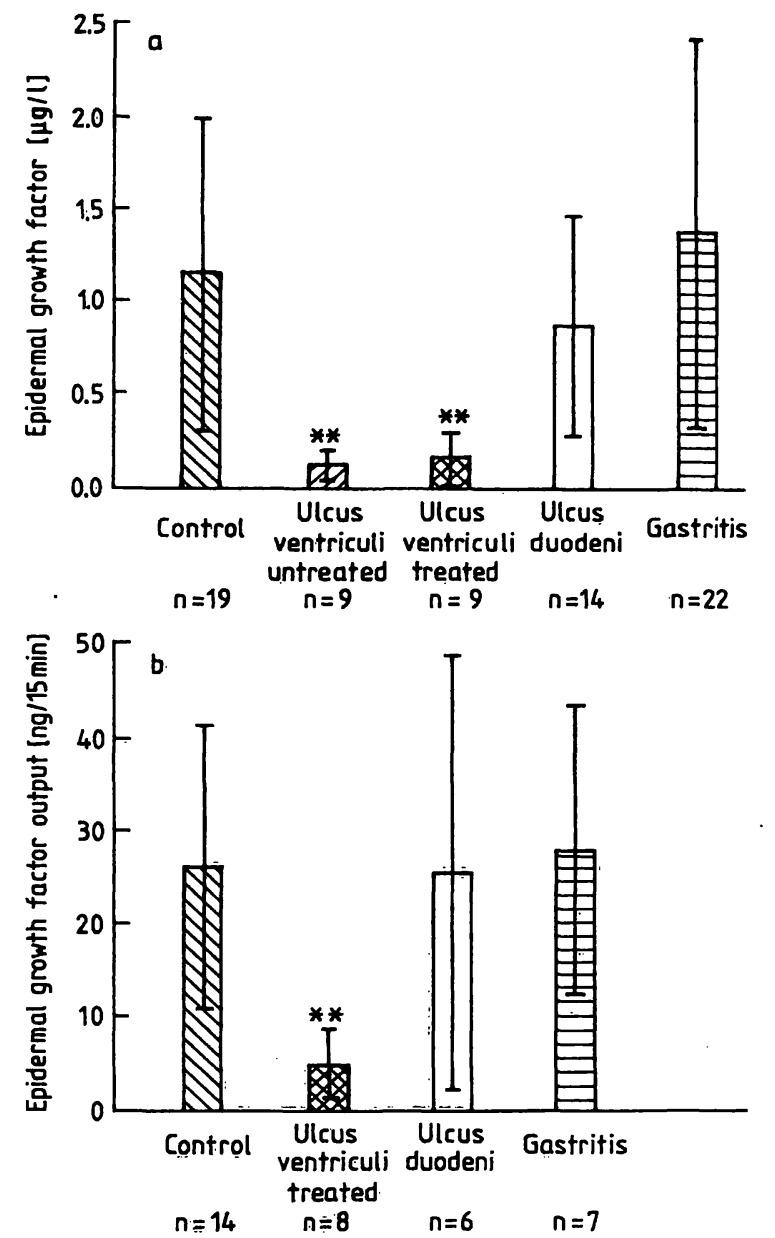

Fig. 4. Epidermal growth factor concentration and output in gastric juice.

Concentrations (a) and outputs (b) of the examined groups show a clear decrease in patients with gastric ulcer, whereas duodenal ulcer and gastritis are not accompanied by a decrease of epidermal growth factor in gastric juice.

All values are means $\pm S D$.

$* *=\mathrm{p}<0.01$ compared with healthy control.

\section{Discussion}

We have developed an ELISA for the measurement of epidermal growth factor in body fluids, which has certain advantages, such as shorter incubation time, economical consumption of antibodies $(1: 150000$ and $1: 15,000$ final dilution of monoclonal and polyclonal antibodies, respectively) and high sensitivity,

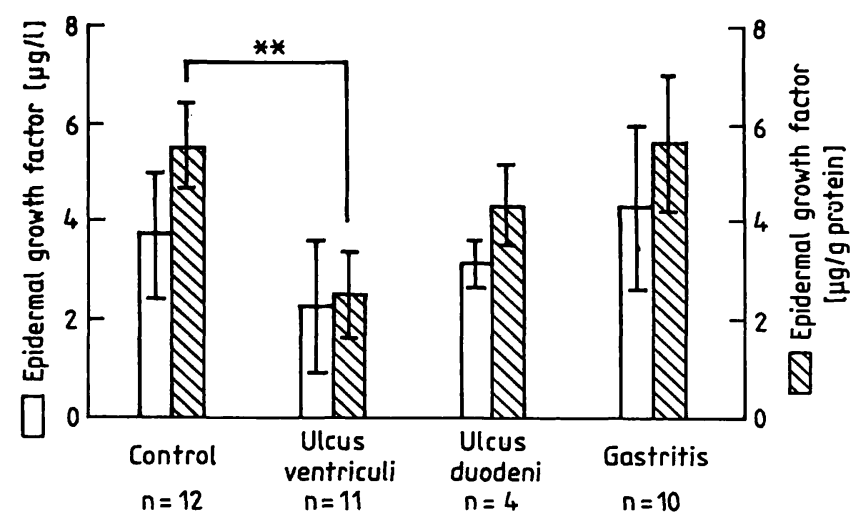

Fig. 5. Epidermal growth factor concentration and ratio of epidermal growth factor concentration to total protein concentration in saliva.

The differences in epidermal growth factor concentration $(\mu \mathrm{g} / \mathrm{l})$ demonstrated in saliva of all investigated collectives are not statistically significant. Referred to total protein ( $\mu \mathrm{g} / \mathrm{g}$ protein) it is decreased significantly in gastric ulcer patients. All values are means $\pm \mathrm{SD}$ $* *=\mathrm{p}<0.01$ compared with healthy controls

the detection limit being $20 \mathrm{ng} / \mathrm{l}$. Changing the incubation time ( $4 \mathrm{~h}$ or overnight) leads to slight shifts of the detection limit. The increased sensitivity, compared with multiple-step-assay-variants using the same antibodies, might be explained by the application of all immunoreactive components in a single incubation phase. This means that equilibrium can be attained in the liquid phase, and is not limited to the cramped spatial conditions on the wall of microtitre plates.

The assay system described above proved to be superior to all other ELISA variants that were tried. A similar assay using rabbit anti-mouse-epidermal growth factor antibodies against human epidermal growth factor (immunological cross-reactivity about $50 \%$ ) was found to be insufficiently sensitive for our purposes (detection limit $10 \mu \mathrm{g} / \mathrm{l}$ ).

Finally, the polyclonal rabbit anti human epidermal growth factor antibodies (a kind gift from Dr. Gregory, ICI) served its purpose and yielded the expected results under the chosen conditions. The sample di- 

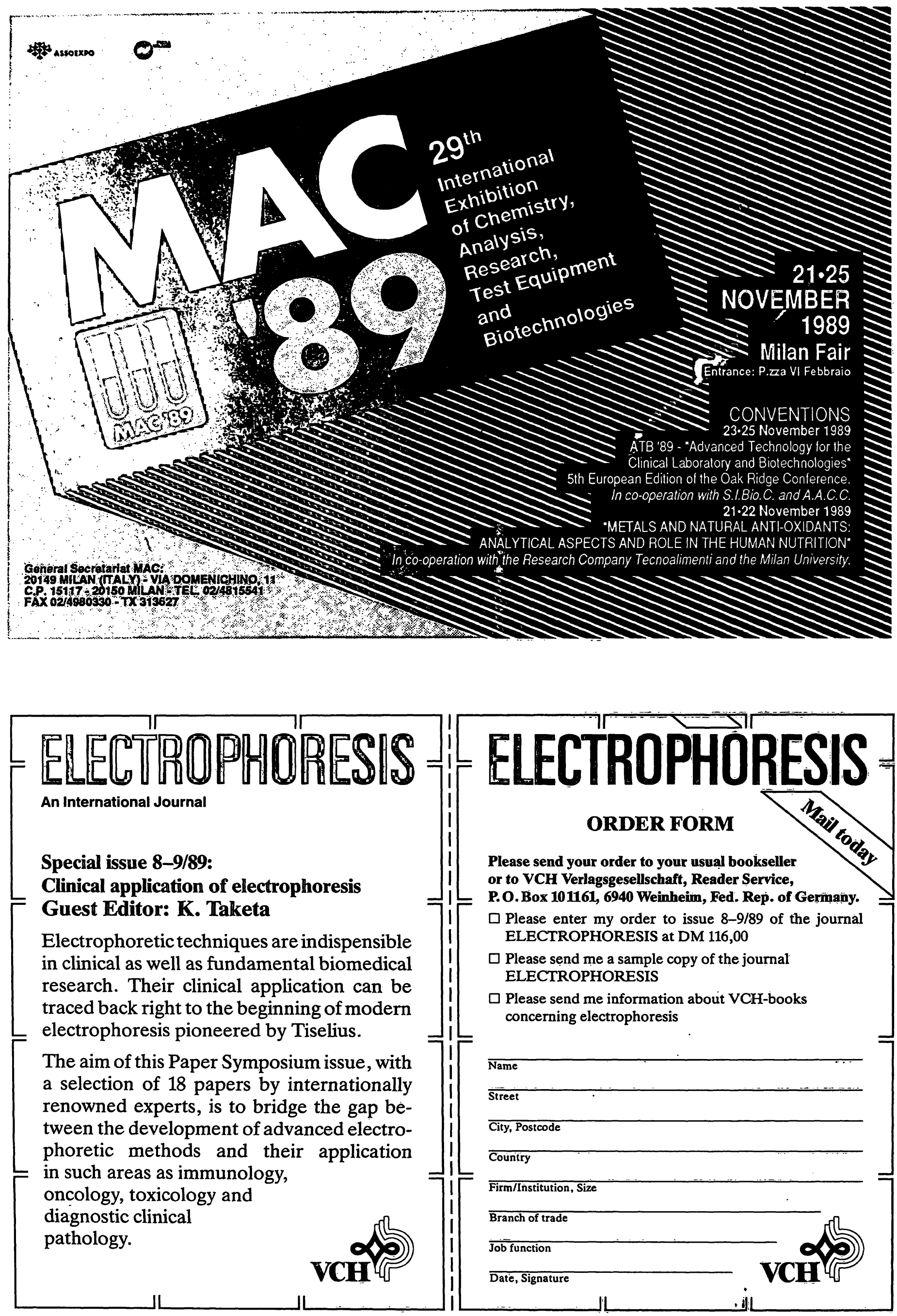


\section{The way out of the desert}

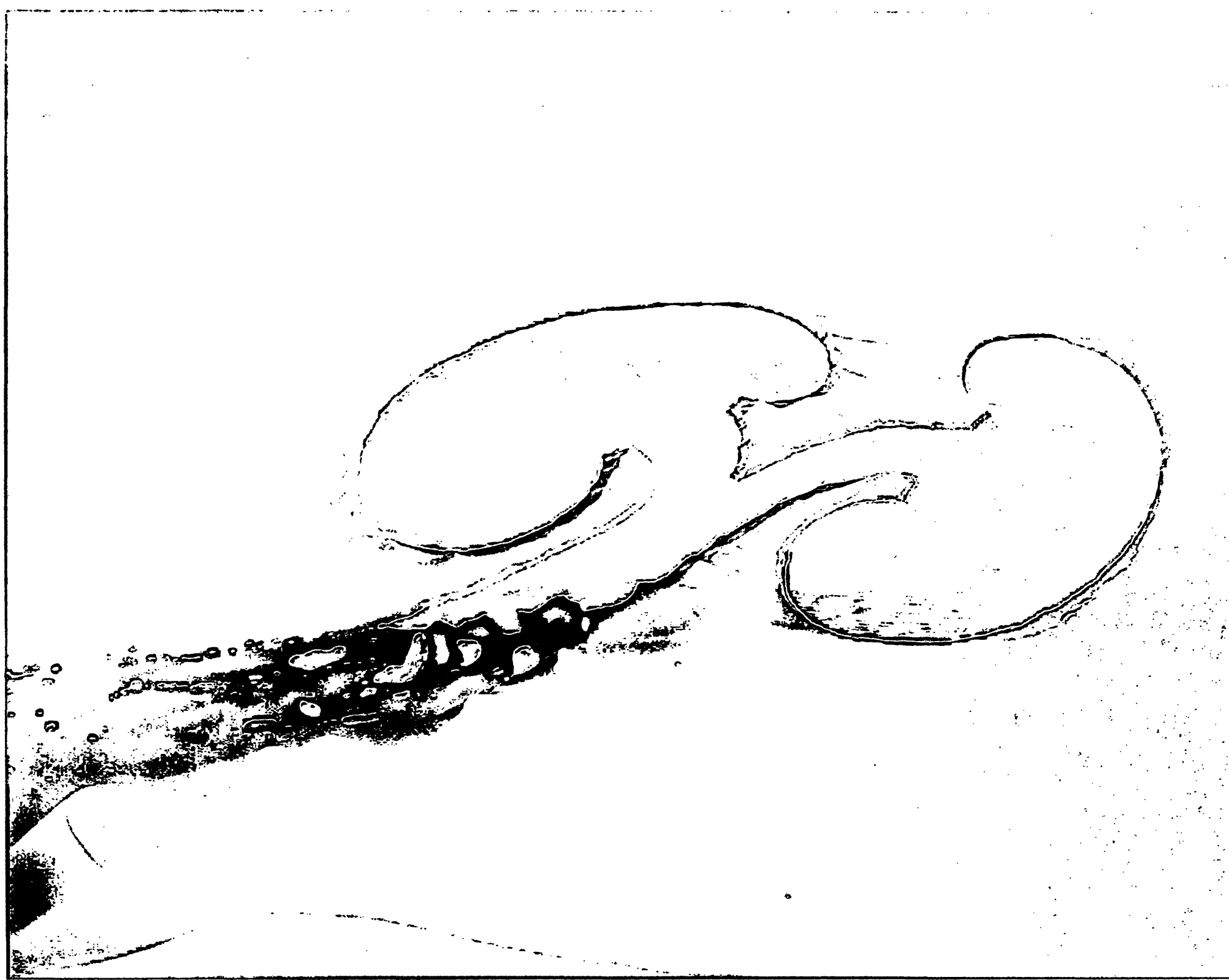

Urine diagnostics with Behring products covering a wide range of renal diseases - e.g. glomerular and tubular proteinurias

You are looking for a method which meets your laboratory needs, Behring offers the appropriate solution - starting from a manual qualitative determination to fully automated quantitative systems.

$$
\begin{aligned}
& \text { IgG } \\
& \text { Transferrin } \\
& \text { Albumin }
\end{aligned}
$$

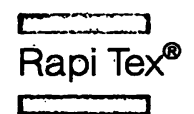

Partigen

$\longrightarrow$

TurbiTimeSystem

\section{$\alpha_{1}-$ Microglobulin}

RBP

Behring Nephelometer 100

Behring Nephelometer 


\section{Inofilleminmmation diagnosis

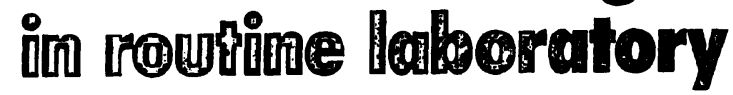

\section{Win the race against time with PAMA elastase assays}

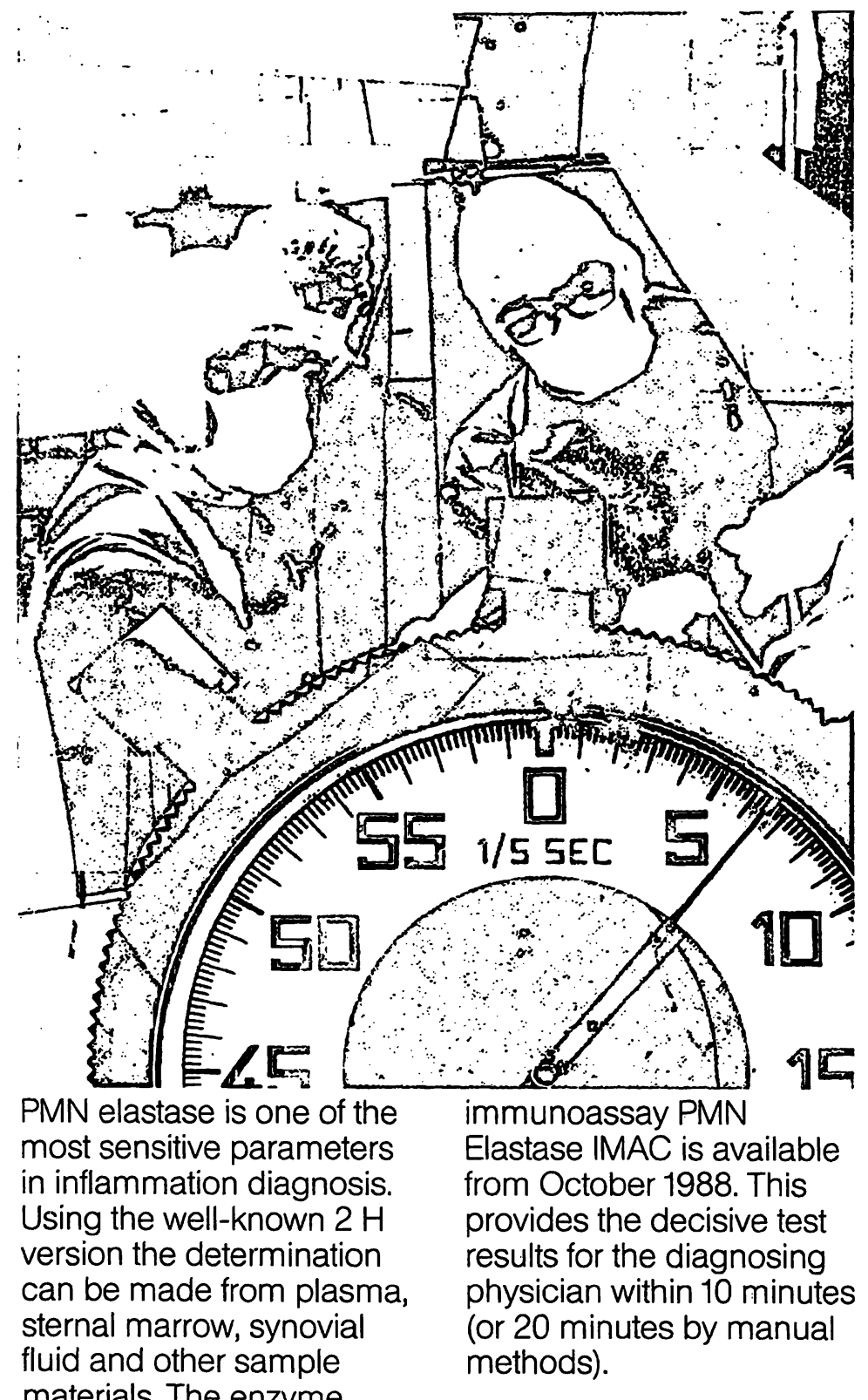

\section{ORIGTUAL IRA Spitzenqualität aus dem Schwarzwald}

Beispiel: Neue Dispergiertechnik:

\section{IKA ${ }^{\circledR}$ - ULTRA-TURRAX ${ }^{\circledR}$ T 25 und T 50}

Hochleistungsdispergiergeräte mit auswechselbaren Dispẹigierwerkzeugen.

2. Zum Bearbeiten von $1 \mathrm{ml}$ bis $20 \mathrm{I}$.

Ceeignet zum Zerfasern, Aufschließen, Homogenisieren etc.

Q Zum homogenisieren von Abwasserproben,

Zur Herstellung von Schlammsuspensionen.

G Geräuscharm durch neue Antriebe.

Fordern Sie Mustergerät an, oder Kundenversuche im IKA ${ }^{\circledR}$-Labor.

IKA ${ }^{\oplus}$ denkt für seine Kunden.
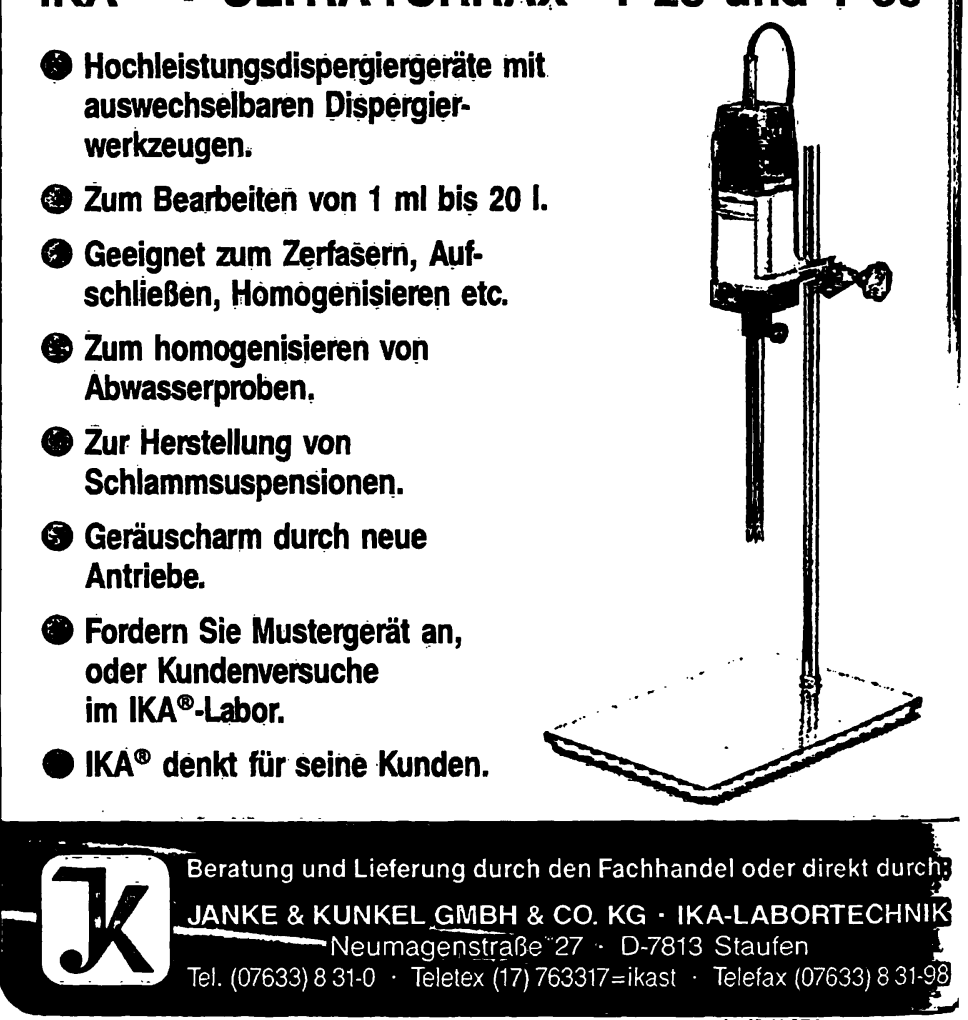

E. Merck

Frankfurter Strasse 250

D-6100 Darmstadt 1

Federal Republic

of Germany 


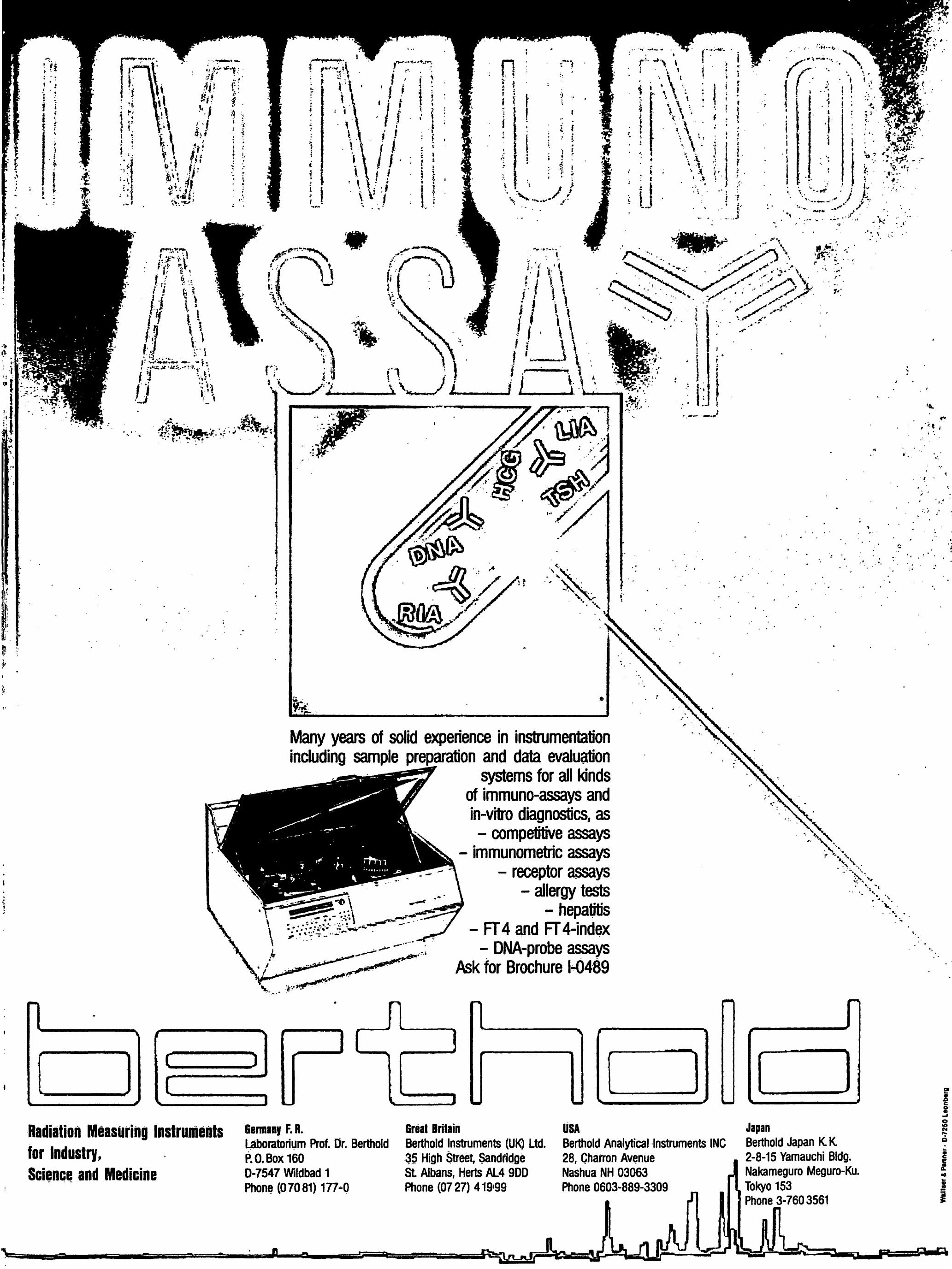


lution curves show good linearity up to a dilution of $1: 2$. Decreased measured concentrations of epidermal growth factor in undiluted gastric juice samples are caused by their low $\mathrm{pH}$ values. The measurement of epidermal growth factor in saliva samples can be hampered by the fact that the high viscosity can lead to pipetting inaccuracies. Low $\mathrm{pH}$ values disturb our assay system due to antibody denaturation, but the immunoreactivity of the epidermal growth factor is unaffected. These problems were avoided by preliminary dilution of all gastric juice and saliva samples with $0.15 \mathrm{~mol} / \mathrm{l}$ phosphate buffer, $\mathrm{pH} 7.4$.

In order to investigate the role of epidermal growth factor in gastroduodenal ulcer disease, we analysed gastric juice and saliva from patients with gastroduodenal ulcer and from healthy controls. Although the discussion of ulcerogenesis emphasizes the importance of the balance between protective and destructive factors, the prevailing and exclusive therapeutic strategy is to diminish or neutralize the acid output in both gastric and duodenal ulcers. These therapeutic concepts acknowledge acid as the causative agent in ulcerogenesis in accordance with Schwarz's dictum "no acid, no ulcer" (13). Nevertheless, the protective aspects have also been subject to investigations and especially in the last few years, epidermal growth factor with its numerous effects has received more attention from gastroenterologic researchers.

In cultures of numerous epithelial cells epidermal growth factor increases proliferation and growth and accelerates differentiation (3). Epidermal growth factor accelerates healing of cysteamine- and acid-induced ulcers in rat duodenum $(14,15)$. Surgical removal of salivary glands retards healing of acid-induced ulcers in the rat, whereas exogeneous (oral or parenteral) epidermal growth factor application demonstrates a cimetidine-like healing effect or is effective in a protective way without affecting acid secretion (16). Epidermal growth factor increases the rate of DNA/RNA synthesis and elevates the activity of ornithine decarboxylase which is required for polyamine synthesis $(17,18,19)$.

It was first reported by Ohmura that ulcer patients show decreased amounts of epidermal growth factor in saliva (9). In this study, it was demonstrated that epidermal growth factor concentrations in patients with gastroduodenal ulcer were lower than in normal subjects, but the results did not differentiate between gastric and duodenal ulcer. We substantiate one of Ohmura's results, i.e. that the highest epidermal growth factor concentrations are present in saliva samples collected in the morning. Our results, however, indicate that the epidermal growth factor concentration in saliva is not subjected to circadian rhythm but is dependent on water balance. Since protein secretion in saliva is adrenergically regulated in contrast to the cholinergically modulated volume secretion, a comparative evaluation of the concentration of epidermal growth factor in saliva alone is difficult due to its dependence on water balance.

We have considered evaluating the total protein concentration and the ratio of epidermal growth factor concentration to the concentration of total protein as a useful reference parameter. In the thirst/fasting tests, the epidermal growth factor output and the ratio of epidermal growth factor concentration to the concentration of total protein were correlated with $\mathrm{r}>0.85$. Applying this ratio to patients and controlș; a decrease of the ratio of epidermal growth factor concentration to the concentration of total protein in saliva was noticed only in gastric ulcer patients, while it remained unchanged in all other collectives.

The concentrations of epidermal growth factor in gastric juice detected by our àssay system are in agreement with data reported by other authors (20). Since there is a considerable intra- and inter-individual fluc: tuation in the secretion rate of gastric juice, we determined epidermal growth factor concentrations and the total volume output of gastric juice. Decreased epidermal growth factor concentrations and decreased epidermal growth factor outputs in gastric juice of patients with gastric ulcer are further indications of the involvement of epidermal growth factor in gastric ulcer disease. Whether the decrease of epidermal growth factor is the cause or the result of gastric ulcer disease remains part of the tantalizing etiologic puzzle requiring further investigation.

To our knowledge, this is the first confirmation that the amount of epidermal growth factor in gastric juice is decreased in gastric ulcer disease. The fact, that epidermal growth factor gastric juice concentrations in patients with duodenal ulcer are within our reference range, however, should not lead to the assumption that epidermal growth factor is not involved in duodenal ulcer disease. Using the working hypothesis that the decrease of epidermal growth factor in gastric juice is connected with or leads to ulcer disease, it would seem to be useful to investigate epidermal growth factor under the influence of anti ulcer drugs such as antisecretagoga or prostaglandin analogues. 


\section{References}

1. Savage, C. R. Jr., Inagami, T. \& Cohen, S. (1972) The primary structure of epidermal growth factor. J. Biol. Chem. 247, 7612-7621.

2. Gregory, H. (1975) Isolation and structure of urogastrone and its relationship to epidermal growth factor. Nature 257, $325-327$.

3. Carpenter, G. \& Cohen, S. (1979) Epidermal growth factor. Ann. Rev. Biochem. 48, 193-216.

4. Thesleff, I., Viinikka, L., Saxen, L., Lehtonen, E. \& Perheentupa, J. (1988) The parotid gland is the main source of human salivary epidermal growth factor. Life Sciences $43,13-18$.

5. Goodwin, C. S., Armstrong, J. A. \& Marshall, B. J. (1986) Campylobacter pyloridis, gastritis, and peptic ulcer. J. Clin. Pathol. 39, 353-365.

6. Gray, J. S. (1939) Inhibition of gastric secretion by extracts of normal male urine. Science 89, 489-490.

7. Konturek, S. J., Dembinski, A., Warzecha, Z., Brzozowski, T. \& Gregory, H. (1988) Role of epidermal growth factor in healing of chronic gastroduodenal ulcers in rats. Gastroenterology 94, 1300-1307.

8. Konturek, S. J. (1988) Role of epidermal growth factor in gastroprotection and ulcer healing. Scand. J. Gastroenterol. $23,129-133$

9. Ohmura, E., Emoto, N., Tsushima, T., Watanabe, S., Takeuchi, T., Kawamura, M., Shigemoto, M. \& Shizume, K. (1987) Salivary immunoreactive human epidermal growth factor (IR-hEGF) in patients with peptic ulcer disease. Hepatogastroenterol. 34, 160-163.

10. Bradford, M. M. (1976) A rapid and sensitive method for the quantitation of microgram quantities of protein utilizing the principle of protein-dye binding. Anal. Biochem. $72,248-254$.

11. Gallati, H. \& Pracht, I. (1985) Peroxidase aus Meerettich: Kinetische Studien und Optimierung der Peroxidase-Aktivitätsbestimmung mit den Substraten $\mathrm{H}_{2} \mathrm{O}_{2}$ und $3,3^{\prime}, 5,5^{\prime}-$ Tetramethylbenzidin. J. Clin. Chem. Clin. Biochem. 23, 453-460.
12. Sachs, L. (1978) Der Vergleich zweier unabhängiger Stichproben: U-Test von Wilcoxon, Mann und Whitney. In: Angewandte Statistik (Sachs, L., ed.) Springer Verlag, S. 230-238

13. Schwarz, K. (1910) Über penetrierende Magen- und Jejunalgeschwüre. Beitr. Klin. Chir. 67, 96-128.

14. Kirkegaard, P., Olsen, P. S., Poulsen, S. S. \& Nexo, E. (1983) Epidermal growth factor inhibits cysteamine-induced duodenal ulcers. Gastroenterology 85, 1277-1283.

15. Olsen, P. S., Poulsen, S. S., Therkelsen, K. \& Nexo, E. (1986) Oral administration of synthetic human urogastrone promotes healing of chronic duodenal ulcers in rats. Gastroenterology 90, 911-917.

16. Olsen, P. S., Poulsen, S. S., Therkelsen, K. \& Nexo, E. (1986) Effect of sialoadenectomy and synthetic human urogastrone on healing of chronic gastric ulcers in rats. Gut 27, 1443-1449.

17. Johnson, L. R. \& Guthrie, P. D. (1980) Stimulation of rat oxyntic gland mucosal growth by epidermal growth factor Am. J. Physiol. 238, G45-G49.

18. Feldman, E., Aures, J. D. \& Grossman, M. I. (1978) Epidermal growth factor stimulates ornithine decarboxylase activity in the digestive tract of mouse. Proc. Soc. Exp. Biol. Med. 159, 400-402.

19. Maudsley, D. V., Leif, J. \& Kobayashi, Y. (1976) Ornithine decarboxylase in rat small intestine: Stimulation with food or insulin. Am. J. Physiol. 231, 1557-1561.

20. Joh, T., Itoh, M., Katsumi, K., Yokoyama, Y., Takeuchi, T., Kato, T., Wada, Y. \& Tanaka, R. (1986) Physiological concentrations of human epidermal growth factor in biological fluids: use of a sensitive enzyme immunoassay. Clin. Chim. Acta 158, 81-90.

Prof. Dr. E. Köttgen

Institut für klinische Chemie

Universitätsklinikum Rudolf Virchow

Spandauer Damm 130

D-1000 Berlin 19 
